\title{
Factors affecting variation in mortality of marine Atlantic salmon Salmo salar in Scotland
}

\author{
Silvia Soares ${ }^{1, *}$, Alexander G. Murray ${ }^{2}$, Mags Crumlish ${ }^{1}$, James F. Turnbull ${ }^{1}$, \\ Darren M. Green ${ }^{1}$
}

\author{
${ }^{1}$ Institute of Aquaculture, School of Natural Sciences, University of Stirling, Stirling FK9 4LA, UK \\ ${ }^{2}$ Marine Scotland Science, Marine Laboratory, Victoria Road, PO Box 101, Aberdeen AB11 9DB, UK
}

\begin{abstract}
Databases of site production have an important role to play in the investigation and understanding of diseases, since they store valuable amounts of disease and management data. Diseases pose an important constraint to economic expansion of aquaculture. They are dependent on the complex interacting factors of pathogen, environment, and host, and the causes of death can be related to nutritional, environmental, and genetic factors of the host or infectious agents. We examined the drivers of mortality from a single site-production database, which represented one-third of Scottish farmed salmon Salmo salar L. production in 2005, to determine whether mortality 'benchmarking' data could be generalised across sites and production cycles. We show that farm mortality records play an important role in studying mortality losses and identifying of management problems in production. We found that mortalities varied across the months of the year and with the time of year of initial stocking. Production cycles that started in the third quarter of the year had the highest mortality overall. Furthermore, we found site-to-site variation in mortality that may have been caused by either random occurrence of epidemics and environmental events or other local effects.
\end{abstract}

KEY WORDS: Mortality $\cdot$ Disease $\cdot$ Database $\cdot$ Aquaculture

Resale or republication not permitted without written consent of the publisher

\section{INTRODUCTION}

Aquaculture is the fastest growing food-producing sector in the world and an important industry in Scotland. Within the UK, Scotland is the main source of salmon and is the source of $80 \%$ of UK aquaculture production. Furthermore, Scotland is the largest producer of farmed salmon in the EU (Marine Scotland Science 2012a), producing some $154000 \mathrm{t}$ in 2010 (Marine Scotland Science 2011). In 2010, freshwater production of smolts stayed constant (36.9 million), with over half ( $62 \%)$ being first-year smolts (S1) and the remainder being half-year smolts $\left(\mathrm{S}^{1 / 2}\right)(38 \%)$, and seawater production of harvested adult fish increased by $6.9 \%$ (Marine Scotland Science 2011).
Diseases pose an important constraint to economic expansion of aquaculture (Bondad-Reantaso et al. 2005, Murray \& Peeler 2005, Subasinghe 2005), and can cause mortality, inadequate growth and poor food conversion, increased production costs, and interrupted production schedules (Hedrick 1998). Different diseases may lead to different levels of mortality, with some highly virulent diseases manifesting no mortality in some years. Mass mortality can also be associated with environmental causes, such as seasonal factors or storms (Pillay \& Kutty 2005, Soares et al. 2011).

Disease outbreaks are generally caused by several factors. Infectious diseases require the presence of the pathogen, combined with the optimal environmental conditions for the disease and a susceptible 
host (Snieszko 1974, Hedrick 1998). Prevention is a key element in the control of disease establishment (Wagner et al. 2002). A good level of understanding of the various factors predisposing to or causing diseases in farmed fish (Menzies et al. 1996) allows more efficient disease control in fish populations. Early and precise diagnosis, effective prevention measures and accurate epidemiological surveys are essential for minimizing the impact of infectious and non-infectious diseases in fish culture.

In the production of marine salmon, the variation in data management among sites is broad, as is seen in other agricultural sectors such as the dairy industry (Kelton et al. 1997). Site management databases may vary from simple and paper-based through to complex computerised systems (Soares et al. 2011). A wide range of information is recorded in these databases, which often includes water temperature, stock origin, age, feed intake and mortality. These databases have an important role to play in the investigation and understanding of diseases, since they store valuable data for epidemiologists and can allow quantification of production losses over time. Furthermore these data can facilitate development of effective disease control strategies (Menzies et al. 1996, Crockford et al. 1999) through epidemiology.

One of the most important variables recorded at the farm level is fish mortality rate (MacIntyre 2008, Anonymous 2009, Soares et al. 2011), which may include the cause of death, e.g. environmental problems, predators or disease (MacIntyre 2008, North et al. 2008). Mortality records are essential for investigating patterns of losses across the production cycle, to benchmark expected mortality across time and monitor progress towards production goals (Dewey 2008, Soares et al. 2011). The identification of unusual mortality losses in fish production may help farm managers to identify and control health and management problems or to alert regulators to an emerging disease (Soares et al. 2011, 2012).

The analysis and the identification of risk factors can be used to identify the factors that contribute to variation in mortality and that can lead to fluctuations in normal mortality (i.e. benchmarking). Such analyses have been performed to understand patterns of mortality and their causes in pigs (Chagnon et al. 1991, Shankar et al. 2009) and poultry (Carver et al. 2000, Tabler et al. 2004). A preliminary investigation into patterns of mortality in salmon was performed by Soares et al. (2011), who found fluctuations in mortality rates and constructed a demonstrative benchmark for salmon mortality in Scotland.
In this study, we built on this analysis to examine the causes of mortality and explanatory factors for variations in mortality, to determine whether this mortality benchmark can be generalised, or whether it is dominated by site-specific and unpredictable effects. We investigated which risk factors (such as temperature, age, or site) were associated with variation in mortality during the marine phase of Atlantic salmon production. These risk factors were selected based on previous studies, where they were found to be associated with disease (e. g. infectious pancreatic necrosis [IPN] and furunculosis) and mortality in Atlantic salmon (Jarp et al. 1995, Wheatley et al. 1995, Jarp \& Karlsen 1997, Murray et al. 2004). For instance, the risk of IPN outbreaks is associated with geographical location of site and age of fish transfer (Jarp et al. 1995). Our study used a site production database from a single company, which represented one-third of Scottish farmed salmon in 2005 (Soares et al. 2011). A general linear model was applied to identify and quantify any patterns identified within the mortality records.

\section{MATERIALS AND METHODS}

\section{Data collection}

We used a site production database provided by a single company. This database encompassed over 60 million Atlantic salmon smolts that were moved into 83 marine production sites located on the western coast of Scotland (Soares et al. 2011). We extracted data from a Business Objects ${ }^{\mathrm{TM}}$ database, which was developed at Marine Scotland Science (Soares et al. 2011) and contained production data concerning mortality causes, mortality losses, smolt input, and harvest. The data recorded mortality — rather than presence of disease - and therefore chronic or subclinical diseases which were not fatal did not feature. Both statutorily notifiable and non-notifiable diseases were recorded (Marine Scotland Science 2012b).

\section{Definition of production cycle}

In this study, the production cycle was the study unit, rather than the site. A production cycle is defined as the time between input of fish into a marine site and their removal for harvest, and one site may host multiple production cycles over time. The length of the production cycle varied from 54 to $124 \mathrm{wk}$, after which the sites were fallowed, and production cycles 
commence throughout the year. Our data comprised 88 complete production cycles for marine salmon between 2000 and 2006. Production cycles with continuous stocking and those that were not complete by the end of the study period were excluded (Soares et al. 2011). The complete data comprised 157 production cycles over 83 sites, which represented $33 \%$ of Scottish sites actively involved in seawater production. Of these sites, 35 had 1 production cycle, 22 sites had 2 and 26 sites had 3. A total of 69 cycles were excluded from the analysis (leaving 88 for study): 31 production cycles were of halibut, and 4 were from experimental units, not for commercial production. An additional 3 cycles were from sites with continuous production that lacked discrete production cycles. Another 25 cycles had incomplete data (including $<7$ mo production data, unfeasibly small input numbers, or no records of input or fish species used), while 6 cycles had a cycle length of $<9$ mo (Soares et al. 2011).

\section{Mortality data}

\section{Daily mortality}

The number of dead fish recovered by different methods (e. g. divers, hand-held baskets, lift-up collectors for dead fish removal, and hand nets) was recorded as cage-level daily mortality. The entries of zero mortality on the database were taken to indicate that during the inspection of a site no dead fish was collected on that day. However, absent records in the database were understood to mean that collection of dead fish by the farmer was not performed on those days. On the days when mortality was not recorded, the daily count was calculated from the total mortalities divided by the number of days since the last count (Hammell \& Dohoo 2005, Aunsmo et al. 2008).

Weekly averages of daily mortality on site were expressed in percentages. We averaged the mortalities over a period of $7 \mathrm{~d}$ to calculate mean daily mortality for the week. Median week-based mortality, expressed as percentage mortality per day, was used to compare with the standard curve of mortality (Soares et al. 2011). The count of fish on site as recorded in the database was the denominator used for mortality calculation, which accounted for transfers into and out of the site during the production cycle. Production cycle was considered the study unit, and therefore betweencage transfers were not a concern. Despite our aggregation of mortality at weekly intervals, for ease of interpretation all mortality is reported below as 'percent per day' $\left(\% \mathrm{~d}^{-1}\right)$.

\section{Cause of death}

Mortality in the site production database was attributed by the farmer to one of 52 pre-assigned mortality causes. To simplify, we re-grouped mortality causes with records in the database into 5 categories (Table 1): unknown causes, production, infectious diseases, environment and predation. In this analysis, a week positive to a mortality cause meant that the cause was recorded at least $1 \mathrm{~d}$ that week. The mortality causes were identified in the database through a mortality code. There were no metadata detailing how mortality causes were originally assigned on-farm. However, events with abnormal mortality levels are usually investigated, and it is highly likely that the farmer's diagnosis is supported by veterinary- or laboratory-based diagnosis in such cases. For infectious pancreatic necrosis (IPN), 2 mortality codes were given to distinguish between suspected and confirmed outbreaks of IPN. In this paper, an IPN-positive week is one with mortalities attributed to confirmed IPN. Pancreatic disease (PD) was only coded as suspected. The remaining codes for diseases did not distinguish between suspected and confirmed outbreaks.

\section{Production cycles grouped by quarters of initial stocking}

Production cycles were grouped by the farm manager into quarters according to the month that the production cycle started, named Q1 to Q4. These quarters do not rigorously follow month boundaries, with Q1 ranging from January to early March; Q2 from March until the end of June; Q3 from July until the end of September, and Q4 from October to the end of December. For example, any production cycle that started at the end of the year (mid to late December) was included in the Q1 period because the conditions and management activities planned by farmers from mid to late December were similar to those in the remainder of the Q1 period. Similar flexibility was also applied for the other quarterly periods.

\section{Statistical analysis}

General linear models in the form of analysis of covariance (ANCOVA) were used to investigate the relationship between mortality and explanatory variables. ANCOVA was performed in Minitab statistical software version 15. There was a large quantity of 
Table 1. Salmo salar. Causes of mortality grouped into 5 categories based on production databases at Scottish fish farms. No. of cycles: no. of production cycles affected. Proportion (\%) of total mortality: contribution (\%) of individual diseases to total recorded mortality. For specific mortality causes of interest, their contribution to overall mortality is indicated

\begin{tabular}{|c|c|c|}
\hline Cause of mortality & $\begin{array}{l}\text { No. of } \\
\text { cycles }\end{array}$ & $\begin{array}{l}\text { Proportion }(\%) \text { of } \\
\text { total mortality }\end{array}$ \\
\hline Unknown & 88 & \\
\hline Blind & 4 & \\
\hline Decomposed & 58 & \\
\hline Deformed jaw & 18 & \\
\hline Disappeared & 2 & \\
\hline Event mortality & 12 & \\
\hline Eye damage & 10 & \\
\hline Fin rot & 49 & \\
\hline Gill damage & 14 & \\
\hline Lesion & 61 & \\
\hline Option missing & 13 & \\
\hline Other & 48 & \\
\hline Physical damage & 74 & \\
\hline Runts & 85 & \\
\hline Samples & 54 & \\
\hline Unidentified & 15 & \\
\hline Production & 88 & \\
\hline Accident loss & 0 & \\
\hline Caught in net & 4 & \\
\hline Cull & 20 & \\
\hline Failed smolts & 62 & \\
\hline Jacks & 13 & \\
\hline Mature & 28 & \\
\hline Net tear & 2 & \\
\hline Normal & 61 & \\
\hline Parr & 42 & \\
\hline Precocious male & 4 & \\
\hline Transfer & 70 & \\
\hline Treatment kill & 32 & \\
\hline Sample weighing & 10 & \\
\hline Smolt transfer & 20 & \\
\hline Suspected cannibalism & 0 & \\
\hline Infectious diseases & 80 & \\
\hline Bacterial kidney disease (BKD) & 7 & $0.5-1.0$ \\
\hline Cardiomyopathy (CMS) & 8 & $0.5-1.0$ \\
\hline Fungus & 9 & $\leq 0.5$ \\
\hline $\begin{array}{l}\text { Infectious pancreatic necrosis } \\
\text { (confirmed-IPN) }\end{array}$ & 46 & $\geq 2.0$ \\
\hline Moritella & 0 & $\leq 0.5$ \\
\hline Pasteurelosis & 5 & $\leq 0.5$ \\
\hline Rickettsia (SRS) & 4 & $0.5-1.0$ \\
\hline Sea lice & 19 & $\leq 0.5$ \\
\hline Suspected furunculosis & 1 & $\leq 0.5$ \\
\hline $\begin{array}{l}\text { Suspected infectious pancreatic } \\
\text { necrosis (suspected-IPN) }\end{array}$ & 69 & $\geq 2.0$ \\
\hline $\begin{array}{l}\text { Suspected pancreas disease } \\
\text { (PD) }\end{array}$ & 18 & $\geq 2.0$ \\
\hline Environment & 27 & \\
\hline Environmental & 2 & \\
\hline Jellyfish & 5 & \\
\hline Oxygen Starvation & 10 & \\
\hline Plankton bloom & 12 & \\
\hline Storm & 11 & \\
\hline Predation & 82 & \\
\hline Birds & 60 & \\
\hline Mink & 1 & \\
\hline Seals & 80 & \\
\hline
\end{tabular}

data and therefore high statistical power. Thus, many associations would be statistically significant, independent of biologically meaningful effect sizes. Therefore, the sequential sum of squares (Seq SS) and eta-squared $\left(\eta^{2}\right)$ were the measures used to report the variance in mortality explained and p-values were not considered. Seq SS Type I is the reduction in the error sum of squares due to each term and is dependent upon the order of introduction of terms into the model. The $\eta^{2}$ value, ranging from 0 to 1 , describes the proportion of variance explained (in the dependent variable, mortality) by a factor while controlling for the other factors already fitted in the model. $\eta^{2}$ is influenced by the size of the sample and is calculated as:

$$
\eta^{2}=\mathrm{SS}_{\mathrm{factor}} / \mathrm{SS}_{\text {total }}
$$

where $\mathrm{SS}_{\text {factor }}$ is the sum of squares of the factor and $\mathrm{SS}_{\text {total }}$ is the total sum of squares, again dependent on the order of terms in the model.

We selected from the database several factors, including calendar year, calendar month (January to December), calendar week (Weeks 1 to 52), age at sea, temperature, relative feed intake (feed supplied per unit biomass present) and site ID to investigate potential management- and environment-related factors and their potential contribution to variation in mortality. Mortality in our study was recorded in a commercial setting; therefore, sea louse and other treatments would be ongoing. Nevertheless, data covering treatments were not available. In each analysis, mortality was the dependent variable, recorded as a proportion and then transformed using a logarithmic transformation. To investigate the time-scale of mortality events, lagged mortality was calculated using a $1 \mathrm{wk}$ lag interval, corresponding to the actual mortality in the previous week. Temperature and feed intake were continuous predictor variables, calendar year, month, week and age at sea were discrete variables and site was a categorical variable.

\section{RESULTS}

\section{Variation in mortality with seasonal temperature averages}

In 2001 mortality was lowest across the year except in October, which reached a mean mortality of $0.3 \% \mathrm{~d}^{-1}$ (Fig. 1). This peak of mortality 


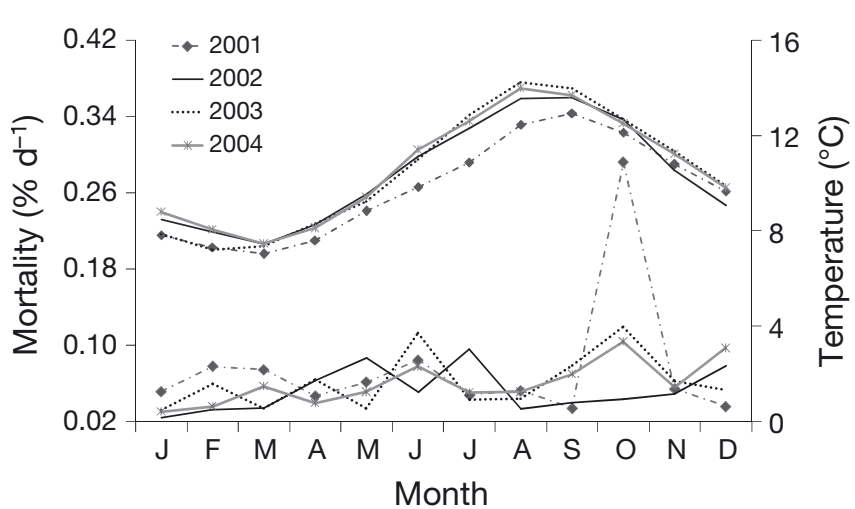

Fig. 1. Salmo salar. Mean week-based mortality of salmon production, expressed as percentage mortality per day, across calendar months from 2001 to 2004 (lower curves), and mean monthly temperatures (upper curves)

was caused by a plankton bloom that affected several sites. The highest variation in mortality across the year was observed in 2003 with a similar mortality pattern in 2004. The year 2002 did not have high mortality overall, but May to July had the highest mortality values. In all years, the main peak of mortality occurred in October, after the temperature peak of July to August (Fig. 1).

We calculated the medians of the weekly mortality averaged across all sites (below, weekly median of daily mortality). In production cycles with initial stocking in autumn and winter, median mortality was generally lower, while it was elevated where initial stocking was in spring and summer. Mortality in autumn/winter production cycles resembled the standard mortality curve (Soares et al. 2011). The elevated mortality in production cycles started in spring and summer coincided with the increase of mean water temperatures at this time of the year (Fig. 2).

\section{Variation in mortality across the production cycle}

Production cycles showed generally elevated mean mortality at the start and at the end of the cycle (Fig. 3). This was thought to be due to fish losses from post-transfer handling and through infectious diseases, particularly PD and cardiomyopathy (CMS) in larger fish. Some spikes of mortality were also observed during the production cycle due to storms (Soares et al. 2011). Mortality peaked in Week 43 $\left(0.21 \% \mathrm{~d}^{-1}\right)$ and in Week $49\left(0.37 \% \mathrm{~d}^{-1}\right)$ with fish mean weight in those weeks of 1.5 and $1.8 \mathrm{~kg}$, respectively. These mortality peaks were caused by storms and plankton bloom, which caused very high mortality at a few sites.

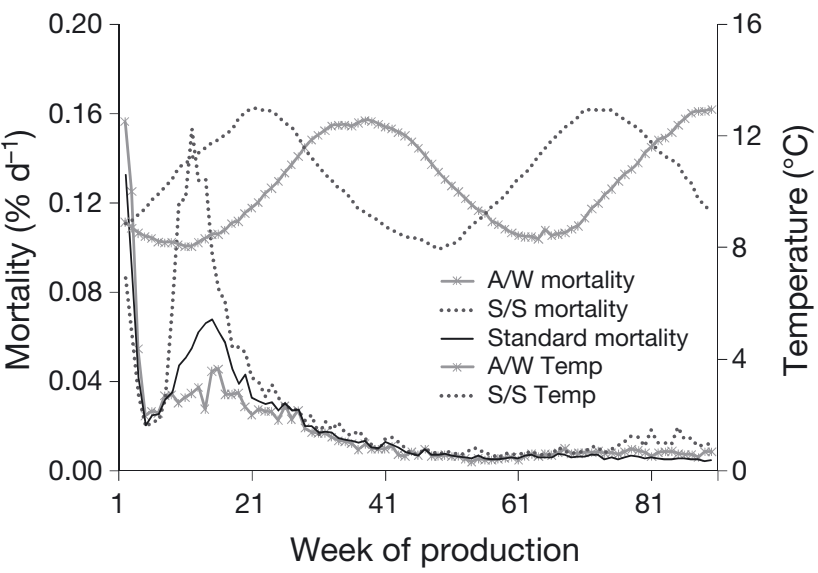

Fig. 2. Salmo salar. Weekly median of daily mortality versus week of production cycle for cycles initially stocked in autumn/winter (A/W) and spring/summer (S/S) (lower curves), and corresponding mean temperatures (upper curves). Standard mortality (solid line in lower curves) is the overall median of mortality, i.e. 'expected losses'

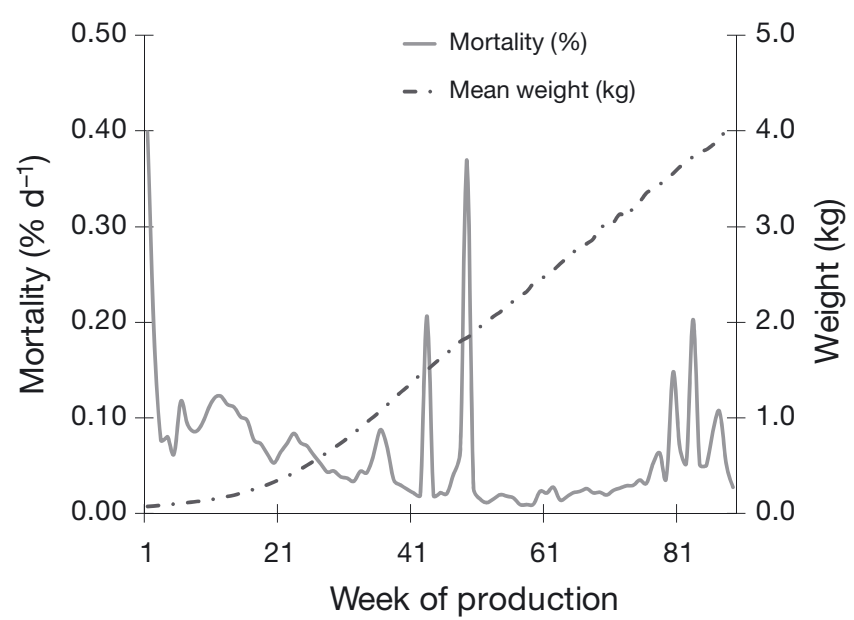

Fig. 3. Salmo salar. Weekly mean of daily mortality and fish mean weight versus week of production cycle

\section{Variation in mortality versus initial stocking quarter}

Mortality plotted against temperature across the year showed bimodal behaviour, with highest mortalities at higher temperatures (Fig. 4b). Production cycles started in Q2 and Q3 showed the highest mortality, associated with temperatures ranging between $9^{\circ} \mathrm{C}$ and $13.3^{\circ} \mathrm{C}$, with a mortality peak at $13^{\circ} \mathrm{C}$ (Fig. 4b). In contrast, Q4 production cycles had the lowest overall percentage mortality across the year followed by Q1 (Fig. 4a). Q2 showed an increase in mortality from Week 21 until Week 31 with a peak in Week $28\left(0.04 \% \mathrm{~d}^{-1}\right)$, (Fig. 4a), which coincided with the highest average temperatures of the year 

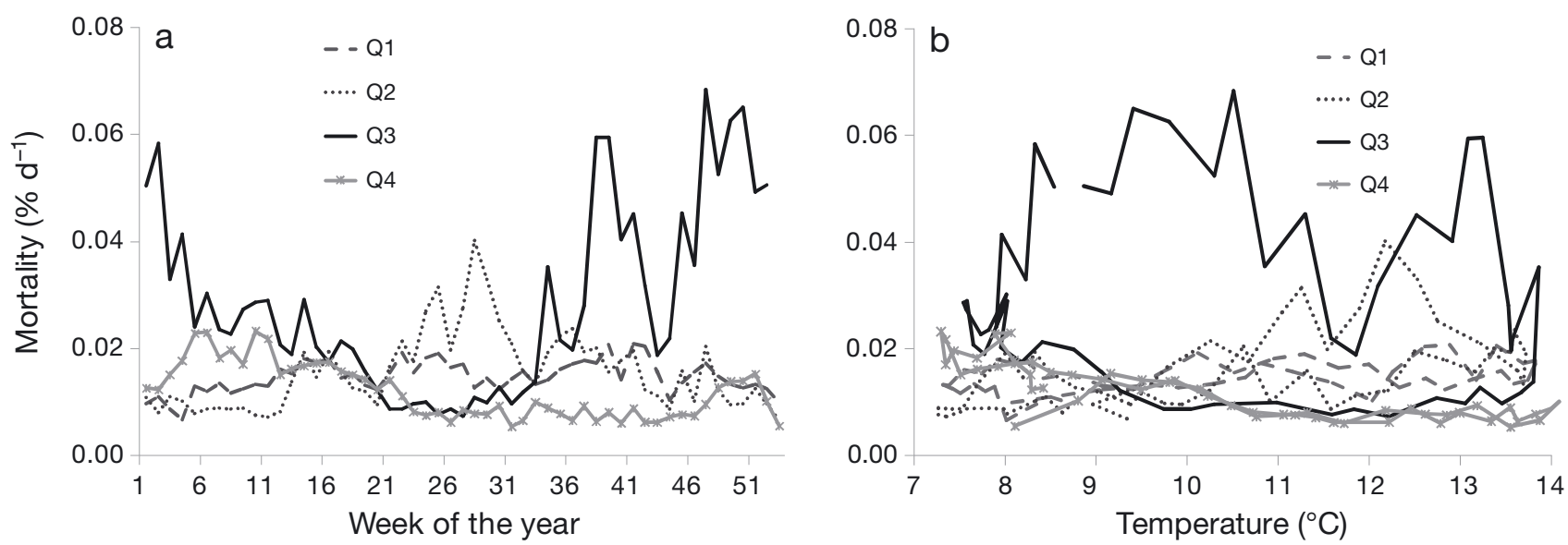

Fig. 4. Salmo salar. Weekly median of daily mortality against (a) week of the year and (b) mean temperature, with production cycles grouped by quarter of initial stocking (Q1-4)

(Fig. 4b). Q1 had the lowest dispersion of weekly median of daily mortality $(0.007-0.02 \%)$ and Q3 had the highest dispersion $(0.007-0.07 \%)$.

The weekly median of daily mortality of production cycles grouped by quarters of initial stocking was compared with the 'benchmark' standard mortality curve, defined as the median daily mortality across all production cycles (Soares et al. 2011). This benchmark aims to allow unusual mortality levels to be identified (Fig. 5). Production cycles started in Q3 showed a higher level of mortality across the production cycle, with 2 mortality peaks in the early weeks (Weeks 5 to 40) and in the last weeks (after Week 68). For production cycles started in the remaining quarters (Q1, Q2 and Q4), the mortality curve followed more closely the standard mortality curve. Q1 cycles had lower mortality levels early on (until Week 30) compared with the standard mortality curve, and Q4 cycles had relatively low mortality levels later on

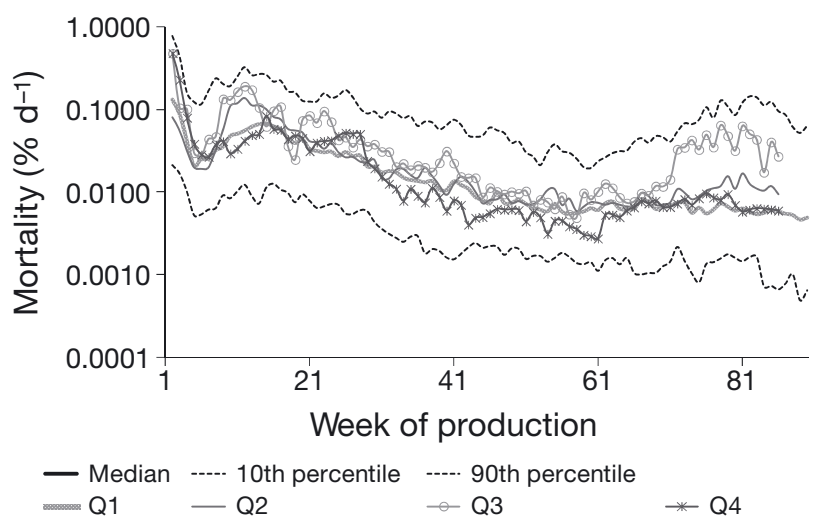

Fig. 5. Salmo salar. Mortality time series for production cycles grouped by quarter of initial stocking (Q1-4), compared with the overall median of expected mortality losses, i.e. the standard mortality curve (after Week 30). Mortality peaked from Weeks 5 to 15 for production cycles started in Q2. The 'noise' towards the end of cycles begun in Q3 is due to the small number of such production cycles (7) started in this quarter, compared with cycles starting in other quarters (25 for Q1, 29 for Q2, and 27 for Q4).

\section{Variation of mortality and its drivers}

The variation in mortality associated with each covariate was generally low across all covariates $\left(\eta^{2}\right.$ $<10.1 \%$ ) with the exception of larger effects of site $\left(\eta^{2}=17.6 \%\right)$ and sea age $\left(\eta^{2}=10.1 \%\right)$ (Fig. 6). Age itself is related to different life stages of fish, different fish sizes, and varying susceptibility to particular diseases and sensitivity to environmental change.

Site was combined with other covariates in a multivariate model, including calendar year, calendar

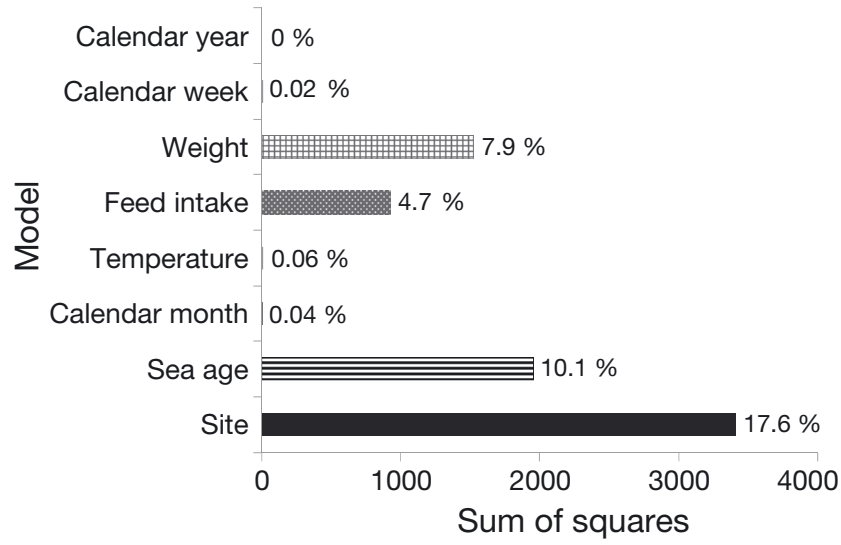

Fig. 6. Salmo salar. Analysis of covariance for mortality data: total sums of squares (bars) and r-squares models (percentages) for univariate analysis of several covariates 
month, calendar week, fish weight, feed intake, temperature, and sea age (Fig. 7) to investigate confounding effects between site and other covariates on mortality. Site was entered into the model either before (Fig. 7a) or after (Fig. 7b) the other covariate(s) to test for confounding effects. In all models, regardless of the order of entry of model terms, where site was included, it was the largest contributor to variance in mortality (Fig. 7). In all models where age was included, it accounted for 10 to $12 \%$ of variation in mortality (Fig. 7). Sea age and site were relatively independent, as might be expected given all sites hosted complete production cycles.

The 1 wk lag term was combined with other variables - calendar year, calendar week, weight, feed intake, temperature, calendar month, and age - to investigate the effects of serial correlation and potential confounding effects in our earlier results (Fig. 8). For each one of the models, the $1 \mathrm{wk}$ lag term was entered in the model as either the first (Fig. 8a) or last term (Fig. 8b). Mortality of the previous week is highly correlated with the mortality of the week in question (Fig. $8 ; \eta^{2}=71 \%$ ). The $1 \mathrm{wk}$ lag term contributed substantially to variation in mortality in all 2-predictor models examined, where it was combined with 1 other variable (temperature, weight, year, week or month), irrespective of the order of the model terms. In the models with all the remaining predictor variables, the $1 \mathrm{wk}$ lag term showed only a slight decrease in its $\eta^{2}$ value and still made a substantial contribution to variation in mortality.

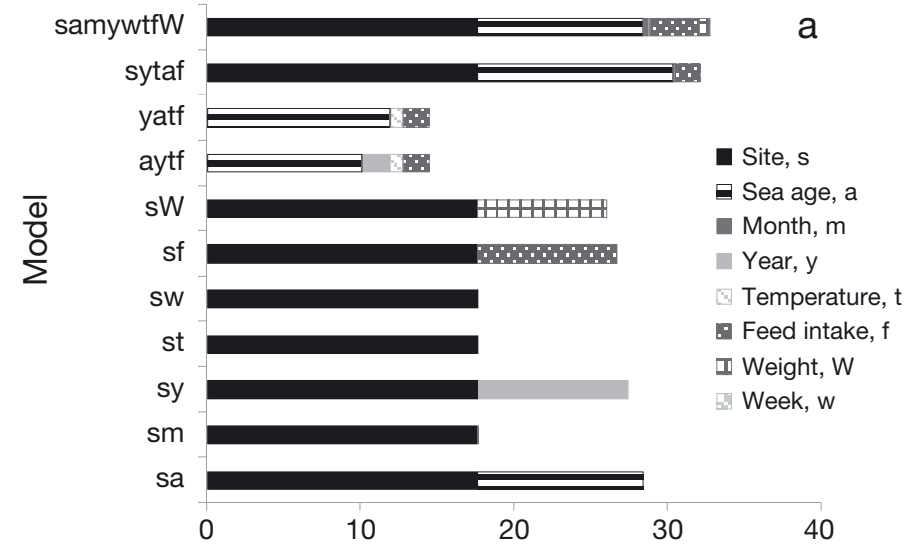

Fig. 7. Salmo salar. Values of $\eta^{2}$ (percentage of the variance in mortality explained by terms) for different models of mortality, with site as (a) first term and (b) last term. Other terms were entered into each model in the order (left to right) they appear on the graph bars. Week, month and year are calendar time

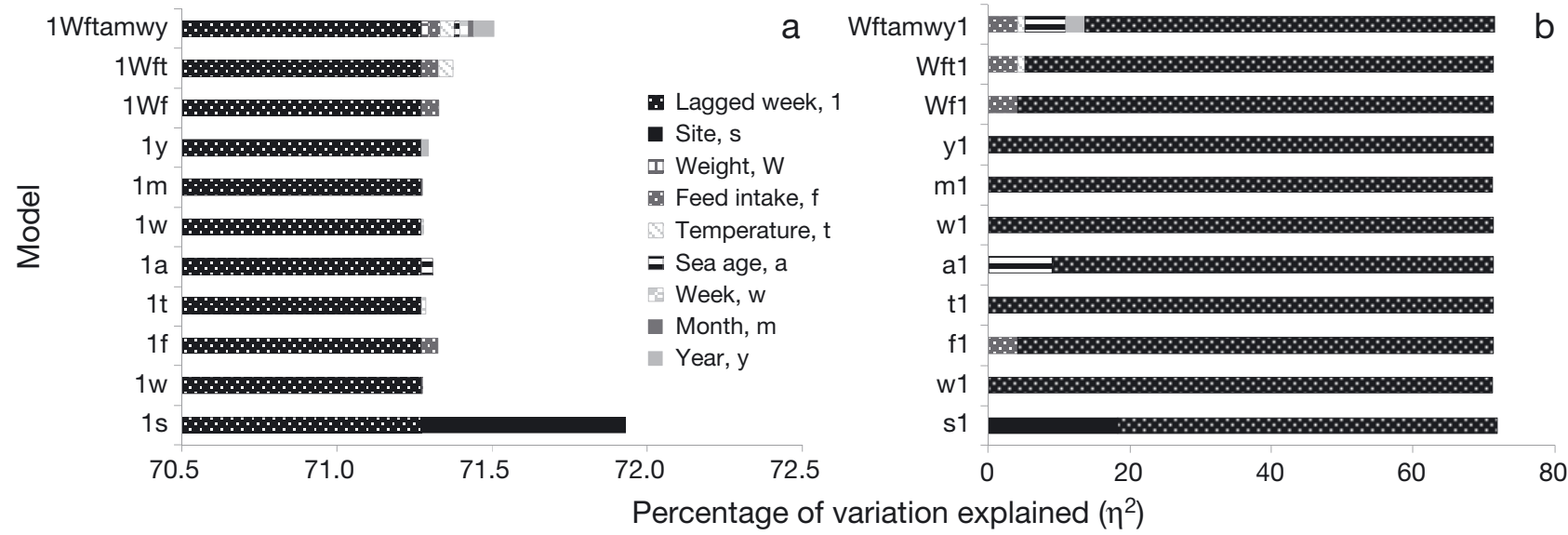

Fig. 8. Salmo salar. Values of $\eta^{2}$ (percentage of the variance in mortality explained by terms) for different models of mortality, with lagged week as (a) first term and (b) last term. Other terms were entered into each model in the order (left to right) they appear on the graph bars. Lagged week is a $1 \mathrm{wk}$ lag term; week, month and year are calendar time 


\section{DISCUSSION}

The aim of this study was to investigate the variation observed in mortalities encountered during the marine production cycle of Atlantic salmon and the proximal causes of this variation.

This analysis was beneficial in identifying the variables that contribute to variation in mortality and that can lead to fluctuations from normal mortality. In our model, site was found to be a major contributor. Broadly speaking, variations in mortality can be attributed to (1) intrinsic differences between variables such as site or year (environmental, weather, or local effects, and varying management practices that may affect fish of different ages); or (2) stochastic events, such as the occurrence of specific disease outbreaks or catastrophes at particular times and places, for example, storms or plankton blooms (Pillay \& Kutty 2005, Soares et al. 2011). Moreover, plankton blooms, such as of jellyfish, can act as a disease vector, e.g. for bacterial diseases (Ferguson et al. 2010, Delannoy et al. 2011), and therefore cause high mortality some time after the initial event. Ageassociated variation in mortality across the production cycle is covered in detail in Soares et al. (2011).

Limitations of this analysis include the restriction of the data to a single company on the west coast of Scotland. However, given the resources available and the commercial sensitivity of such data, a census of the whole industry would be impractical. The methods employed in this study may also be used within a company as a tool to investigate the drivers of variation in mortality for its own production. At the industry level, this analysis constitutes a preliminary study quantifying patterns in mortality and a depiction of how these were overlaid by fluctuations due to outbreaks of infectious diseases and specific environmental events.

In this study, production cycles from Q3 had the highest mortalities (Figs. 3 to 5). This high mortality may be because smolt transfer occurred during the period of increasing water temperature, when fish are more susceptible to outbreaks of diseases such as PD (Crockford et al. 1999). The small number of production cycles commencing in Q3 was the result of a health-management decision by the company to avoid smolt transfers at this time of the year. This resulted in the less smooth benchmark curve for Q3 cycles.

Site, year, feed intake and the 1 wk lag term contributed to the variance in mortality (Figs. $7 \& 8$ ). Higher temperatures occurred in certain years, for example 2003, which led to higher prevalence of cer- tain infectious diseases (Lannan et al. 1992, Crockford et al. 1999, Cusak et al. 2002), including IPN and $\mathrm{PD}$, and concomitant increased mortality (Soares et al. 2011). Differences in management practices between years and among production cycles on the same site may also be a cause of mortality variability (Wheatley et al. 1995, Crockford et al. 1999). Sitespecific variables that may influence the variation of mortality may have not been fully captured in the other data fields (e.g. temperature or season), leading to a large residual effect associated with site.

The high correlation between mortality in sequential weeks decreased over time, with a significant drop after the second week. This suggests that the majority of mortality events were quite short lived. Hence, we introduced a $1 \mathrm{wk}$ lag term into the models to account for serial correlation in the data.

Feed intake also contributed to on-site variance in mortality. However, the variation associated with feed intake should be considered more as a consequence than as a cause since diseased fish tend to reduce their feed intake in response to loss of appetite and as a fasting strategy (Damsgård et al. 1998, Pirhonen et al. 2003, Ramsay et al. 2004). Additionally, in winter time, fish also reduce feed intake due the lower temperatures (Elliot 1991, Koskela et al. 1997).

\section{CONCLUSIONS}

This study allowed the identification of several possible factors, including site, temperature and age at sea, that may contribute for fluctuations in mortality rates and constitute a risk factor for certain infectious diseases. This variation in mortality can be identified by the use of benchmark analysis (Soares et al. 2011) to quantify possible problems of production either in the industry or at the farm or company level and provide a standard against which levels of unusual mortality can be noted.

A wider database would be of great benefit and would allow the identification of other combinations of factors and resolution of more complex interactions amongst factors. It would also allow a better understanding of the challenges faced by the Scottish salmon industry and support the development of industry-level benchmarks that could help both the commercial sector and regulators in the prevention and control of fish diseases.

Acknowledgements. This research was supported by Marine Scotland Science. 


\section{LITERATURE CITED}

Anonymous (2009) Development of a scheme for monitoring sentinel farms in the UK trout industry. Final report, DEFRA Research Project SARF028. www.sarf.org.uk/ Project\%20Final\%20Reports/SARF028FinalReport.pdf

Aunsmo A, Bruheim T, Sandberg M, Skjerve E, Romstad S, Larssen RB (2008) Methods for investigating patterns of mortality and quantifying cause-specific mortality in seafarmed Atlantic salmon Salmo salar. Dis Aquat Org 81: 99-107

Bondad-Reantaso MG, Subasinghe RP, Authur JR, Ogawa Z and others (2005) Disease and health management in Asian aquaculture. Vet Parasitol 132:249-272

Carver DK, Fertrow J, Gerig T, Correa MT, Krueger KK, Barnes HJ (2000) Use of statistical modelling to assess risk for early poult mortality in commercial turkey flocks. J Appl Poult Res 9:303-318

Chagnon M, D'Allaire S, Drolet R (1991) A prospective study of sow mortality in breeding herds. Can J Vet Res 55: 180-184

Crockford T, Menzies FD, McLoughlin MF, Wheatley SB, Goodall EA (1999) Aspects of the epizootiology of pancreas disease in farmed Atlantic salmon Salmo salar in Ireland. Dis Aquat Org 36:113-119

Cusak RR, Groman DB, Jone SRM (2002) Rickettsial infection in farmed Atlantic salmon in eastern Canada. Can Vet J 42:435-440

Damsgård B, Mortensen A, Sommer AI (1998) Effects of infectious pancreatic necrosis virus IPNV on appetite and growth in Atlantic salmon, Salmo salar L. Aquaculture 163:185-193

Delannoy CMJ, Houghton JDR, Fleming NEC, Ferguson HW (2011) Mauve stingers (Pelagia noctiluca) as carriers of the bacterial fish pathogen Tenacibaculum maritimum. Aquaculture 311:255-257

Dewey C (2008) The use of epidemiology to enhance production animal research. Prev Vet Med 86:244-249

Elliot JM (1991) Tolerance and resistance to thermal stress in juvenile Atlantic salmon, Salmo salar. Freshw Biol 25: 61-70

> Ferguson HW, Delannoy CMJ, Hay S, Nicolson J, Sutherland D, Crumlish M (2010) Jellyfish as vectors of bacterial disease for farmed salmon (Salmo Salar). J Vet Diagn Invest 22:376-382

- Hammell KL, Dohoo IR (2005) Mortality patterns in infectious salmon anaemia virus outbreaks in New Brunswick, Canada. J Fish Dis 28:639-650

> Hedrick RP (1998) Relationship of the host, pathogen, and environment: implications for diseases of cultured and wild fish populations. J Aquat Anim Health 10:107-111

Jarp J, Karlsen E (1997) Infectious salmon anaemia (ISA) risk factors in sea-cultured Atlantic salmon Salmo salar. Dis Aquat Org 28:79-86

Jarp J, Gjevre AG, Olsen AB, Bruheim T (1995) Risk factors for furunculosis, infectious pancreatic necrosis and mortality in post-smolt of Atlantic salmon, Salmo salar L. J Fish Dis 18:67-78

Kelton DF, Bonnett BN, Lissemore KD (1997) Dairy cattle disease data from secondary databases. Use with caution! Proc Int Workshop Genetic Improvement of Functional Traits in Cattle Health, Uppsala, June 1997. Bulletin International Bull Evaluation Service 15:3-10

Koskela J, Pirhonen J, Jobling M (1997) Effect of low temperature on feed intake, growth rate and body composition of juvenile Baltic salmon. Aquacult Int 5:479-487

Lannan CN, Cvitanich JD, Evelyn TPT (1992) Rickettsial disease of salmonids. Informational Report 6. Prepared for the Pacific Northwest Fish Health Protection Committee. http://wdfw.wa.gov/pnfhpc/pubs/ireports/rickettsial.pdf
MacIntyre CM (2008) Water quality and welfare assessment on the United Kigdom trout farms. PhD thesis, University of Stirling

Marine Scotland Science (2011) Scottish fish farm production survey 2010. www.scotland.gov.uk/Publications/2011/11/ $17152846 / 10$

Marine Scotland Science (2012a) Aquaculture-Facts and figures. www.scotland.gov.uk/Topics/marine/Fish-Shellfish/ FactsandFigures

Marine Scotland Science (2012b) Aquaculture-DiseasesNotifiable diseases. www.scotland.gov.uk/Topics/marine/ Fish-Shellfish/18364/18610/diseases/notifiableDisease

Menzies FD, McLoughlin MF, Wheatley SB, Goodall EA (1996) Development of computerized information retrieval system for Atlantic salmon, Salmo salar L., production. Aquacult Res 27:183-190

Murray AG, Peeler EJ (2005) A framework for understanding the potential for emerging diseases in aquaculture. Prev Vet Med 67:223-235

Murray AG, Leschen WA, Kilburn R, Raynard RS (2004) A case-control study for the identification of risk factors behind clinical outbreaks of infectious pancreatic necrosis (IPN). Fisheries Research Services Internal Report No 06/04. Marine Research Services. www.scotland.gov.uk/ Uploads/Documents/ir0604.pdf

North BP, Ellis T, Bron J, Knowles T, Turnbull JF (2008) The use of stakeholder focus groups to identify indicators for the on-farm assessment of trout welfare. In: Branson EJ (ed) Fish welfare. Blackwell, Oxford, p 243-266

Pillay TVR, Kutty MN (2005) Health and diseases. In: Aquaculture: principles and practices, 2nd edn. Blackwell, Oxford, p 201-245

Pirhonen J, Schrecka CB, Renob PW, Ögüt H (2003) Effect of fasting on feed intake, growth and mortality of Chinook salmon, Oncorhynchus tshawytscha, during an induced Aeromonas salmonicida epizootic. Aquaculture 216:31-38

Ramsay JM, Speare DJ, Daley J (2004) Timing of changes in growth rate, feed intake and feed conversion in rainbow trout, Oncorhynchus mykiss (Walbaum), experimentally infected with Loma salmonae (Microspora). J Fish Dis 27: 425-429

Shankar BP, Madhusudhan HS, Harish DB (2009) Pre-weaning mortality in pig-causes and management. Vet World 2: 236-239

> Snieszko SF (1974) The effects of environmental stress on the outbreaks of infectious diseases of fish. J Fish Biol 6: $197-208$

Soares S, Green DM, Turnbull JF, Crumlish M, Murray AG (2011) A baseline method for benchmarking mortality losses in Atlantic salmon (Salmo salar) production. Aquaculture 314:7-12

Soares S, Murray AG, Crumlish M, Turnbull JF, Green DM (2012) Evaluating abnormal mortality as an indicator of disease presence in the Atlantic salmon industry using the receiver operating characteristic (ROC). Aquaculture 370371:136-143

Subasinghe RP (2005) Epidemiological approach to aquatic animal health management: opportunities and challenges for developing countries to increase aquatic production through aquaculture. Prev Vet Med 67:117-124

Tabler GT, Berry IL, Mendenhall AM (2004) Mortality patterns associated with commercial broiler production. Avian Advice 6:1-3

Wagner BG, Wise DJ, Khoo LH, Terhune JS (2002) The epidemiology of bacterial diseases in food-size channel catfish. J Aquat Anim Health 14:263-272

Wheatley SB, McLoughlin MF, Menzies FD, Goodall EA (1995) Site management factors influencing mortalities rates in Atlantic salmon (Salmo salar L.) during marine production. Aquaculture 136:195-207 